\title{
PAST CONFERENCES
}

\section{JOINT MATHEMATICS MEETINGS \\ San Antonio, Texas, USA \\ January 10-13, 2015}

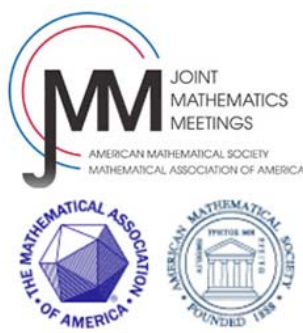

San Antonio again hosted the largest mathematics meeting in the world, the Joint Mathematics Meetings (JMM). This was the $98^{\text {th }}$ annual winter meeting of the Mathematical Association of America (MAA) and the $121^{\mathrm{st}}$ annual meeting of the American Mathematical Society (AMS). The JMM hosted sessions by the Association for Symbolic Logic (ASL), the Association for Women in Mathematics (AWM), the National Association for Mathematicians (NAM), and the Society for Industrial and Applied Mathematics (SIAM).

For more information: http://jointmathematicsmeetings.org/jmm

\section{FORTHCOMING IASE CONFERENCES}

\section{IASE SATELLITE TO 60th WORLD STATISTICS CONGRESS OF THE ISI Rio de Janeiro, Brazil \\ July 22-24, 2015}

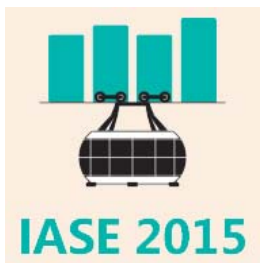

The theme of the 2015 IASE Satellite Conference is 'Advances in Statistics Education: developments, experiences and assessments'. The first two days will feature papers proposed by IASE while the third day will involve representatives of IAOS as well as IASE. The conference will be held at the campus of the Universidade Federal do Estado do Rio de Janeiro (UNIRIO), in the old and beautiful Urca neighborhood of Rio. Proceedings will be published on the IASE website in October.

For more information: http://iase-web.org/conference/satellite15/

\section{0th WORLD STATISTICS CONGRESS OF THE ISI \\ Rio de Janeiro, Brazil \\ July 26-31, 2015}

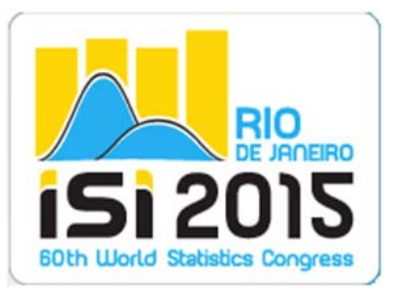

The 60th World Statistics Congress will take place in Rio de Janeiro, Brazil, from July 26-31, 2015. The congress will bring together members of the statistical community to present, discuss, promote, and disseminate research and best practice in every field of statistics and its applications. The Scientific Programme of the 60th Congress will offer delegates innovative and well-balanced presentations, as well as plenty of opportunities for discussion and exchange. A rich and exciting Social Programme is also being developed, with plenty to see and enjoy for participants and their accompanying persons, hoping to make your trip to Rio and taking part in ISI 2015 a memorable experience.

For more information: http://www.isi2015.ibge.gov.br/ 


\section{IASE ROUNDTABLE \\ Berlin, Germany \\ July 19-22, 2016}

IASE Roundtables are small workshop conferences that bring together a selected international group of experts to address a particular theme and to make recommendations from which institutions and individuals engaged in statistical education and training (in developed and developing countries) may benefit. The 2016 IASE Roundtable takes place at the Max Planck Institute in Berlin, Germany, before ICME13 in Hamburg, Germany and has the theme "Promoting the Understanding of Statistics about Society".

\section{INTERNATIONAL CONGRESS ON MATHEMATICAL EDUCATION (ICME 13) Hamburg, Germany July 24-31, 2016}

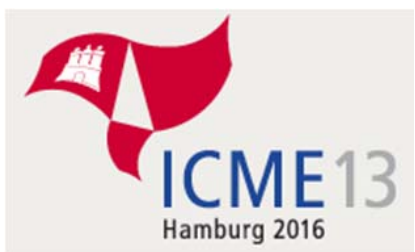

IASE supports a suite of topic study groups on statistics and on probability at each ICME conference. The Society of Didactics of Mathematics (Gesellschaft für Didaktik der Mathematik - GDM) has the pleasure of hosting ICME-13 in Germany. The congress - to be held under the auspices of the International Commission on Mathematical Instruction (ICMI) - will take place at the University of Hamburg. Hamburg is a bustling cosmopolitan port in northern Germany, and with 1.8 million inhabitants, its second largest city.

For more information: http://www.icme13.org/

\section{OTHER FORTHCOMING CONFERENCES}

\section{UNITED STATES CONFERENCE ON TEACHING STATISTICS State College, Pennsylvania, USA \\ May 28-30, 2015}

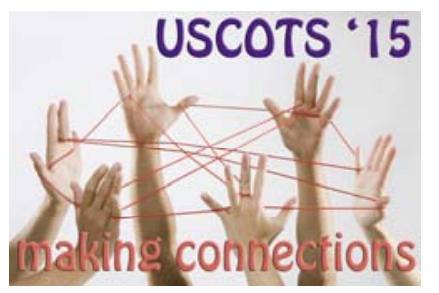

The theme of the sixth biennial United States Conference on Teaching Statistics (USCOTS) is "Making Connections". Teachers of statistics strive to help their students to make connections with each other, to make connections among concepts in the course, and to make connections between statistics and other disciplines. Making professional connections can also help to enhance a statistics teacher's effectiveness, for example by making connections with other statistics teachers and with scholars in fields that use statistics. USCOTS is designed to model good teaching in its lively keynote presentations, interactive breakout sessions, and "poster and beyond" sessions that will engage participants and address how to make connections in four main areas: curriculum, pedagogy, resources, and educational research. USCOTS is hosted by the Consortium for the Advancement of Undergraduate Statistics Education (CAUSE) and is preceded by a variety of workshops that disseminate innovative statistics education projects.

For more information: http://www.causeweb.org/uscots/ 


\section{TURNING DATA INTO KNOWLEDGE: NEW OPPORTUNITIES FOR STATISTICS EDUCATION University of Lisbon, Portugal June 22-23, 2015}

This international conference is an initiative of the Portuguese research project DSL (Developing statistical literacy: Student learning and teacher education) involving the Universities of Lisbon and Évora, and supported by a group of leading international researchers in statistics education who take part in the Scientific Committee. The Conference provides an opportunity to gather researchers, teacher educators and teachers interested in statistics education to exchange experiences and to present and discuss recent research and current projects. This conference includes two invited plenary talks, one plenary discussion panel, thematic keynote addresses, research papers, short oral communications, and poster presentations.

For more information: http://www.statisteduc.ie.ulisboa.pt/home/

\section{STATISTICAL REASONING, THINKING AND LITERACY RESEARCH FORUM Waldhotel Nachtigall in Paderborn, Germany July 26-August 1, 2015}

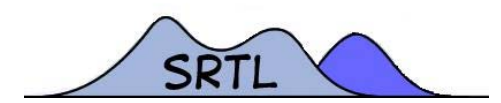

The SRTL International Collaboration began in 1999 to foster innovative research studies that examine the nature and development of statistical literacy, reasoning, and thinking, and to explore the challenge of developing these desired learning goals for students. Co-chaired by Joan Garfield and Dani Ben-Zvi, the SRTL Forums offer scientific gatherings every two years and related publications in journals, and books. The theme of the SRTL-9 Research Forum is Reasoning about Models and Modelling in the Context of Informal Statistical Inference.

For more information: contact Dani Ben-Zvi (dbenzvi@haifa.ac.il)

\section{JOINT STATISTICAL MEETINGS Seattle, Washington, USA August 8-13, 2015}

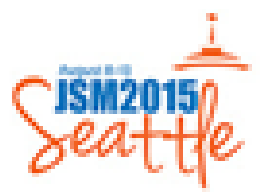

The 2015 Joint Statistical Meetings (JSM) has the theme "Statistics: Making Better Decisions". The largest gathering of statisticians held in North America, JSM is held jointly with the American Statistical Association, the International Biometric Society (ENAR and WNAR), the Institute of Mathematical Statistics, the Statistical Society of Canada, the International Chinese Statistical Association, the International Indian Statistical Association, the International Society for Bayesian Analysis, the Korean International Statistical Association, and the Royal Statistical Society. Attended by over 6000 people, activities of the meeting include oral presentations, panel sessions, poster presentations, continuing education courses, exhibit hall (with state-of-the-art statistical products and opportunities), career placement service, society and section business meetings, committee meetings, social activities, and networking opportunities.

For more information: http://www.amstat.org/meetings/jsm/2015/ 


\section{ROYAL STATISTICAL SOCIETY (RSS) 2015 INTERNATIONAL CONFERENCE Exeter, UK \\ September 7-10, 2015}

ROYAL STATISTICAL SOCIETY

The 2015 Conference of the Royal Statistical Society will take place in Exeter September 7-10, 2015. The main conference will be preceded by a number of short courses and workshops on Monday, 7 September with a welcome reception in the evening. The main conference programme will take place over three days starting on the morning of September 8 and concluding in the late afternoon of September 10. The conference programme will include at least four plenary sessions, as well as over 25 invited sessions covering a broad range of topics. More information will be available from the conference blog later in the year.

For more information: http://www.rssconference.org.uk/programme

\section{JOINT MATHEMATICS MEETINGS Seattle, Washington, USA January 6-9, 2016}

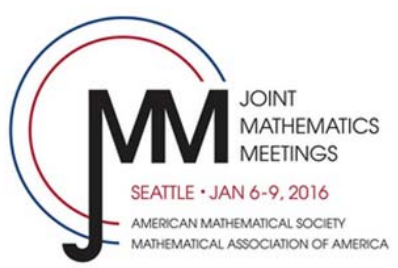

The largest mathematics meeting in the world is coming to Washington State Convention Center in Seattle, one of the most vibrant, green, and relaxing cities in the country. The Mathematical Association of America (MAA) and the American Mathematical Society (AMS) invite you to join them for the next Joint Mathematics Meetings (JMM), which will be the 99th annual winter meeting of MAA and the 122nd annual meeting of AMS. The JMM will again host sessions by the Association for Symbolic Logic (ASL), the Association for Women in Mathematics (AWM), the National Association for Mathematicians (NAM), and the Society for Industrial and Applied Mathematics (SIAM).

For more information: http://jointmathematicsmeetings.org/jmm

\section{JOINT STATISTICAL MEETINGS Chicago, Illinois, USA July 30-August 4, 2016}

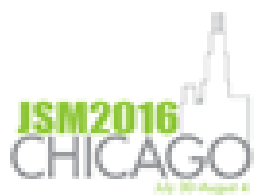

As a preview, the 2016 Joint Statistical Meetings is planned to be held at McCormick Place in Chicago. The series is continued under the auspices of leading societies in statistics and will provide opportunities for presentations, continuing education courses, exhibits, society and section business meetings, committee meetings, social activities, and networking.

For more information see the updates on: http://www.amstat.org/meetings/jsm.cfm 